\title{
The choice of external morphological characters and developmental stages for tadpole-based anuran taxonomy: a case study in Rana (Sylvirana) nigrovittata (Blyth, 1855) (Amphibia, Anura, Ranidae)
}

\author{
S. Grosjean \\ Département de Systématique et Evolution, UMS 602 Taxinomie et Collections - Reptiles et Amphibiens, Case 30, \\ Muséum National d'Histoire Naturelle, 25 rue Cuvier, 75005 Paris, France, e-mail: sgrosjea@mnhn.fr
}

Keywords: Tadpole, Rana (Sylvirana) nigrovittata, Ranidae, external morphology, morphometry, internal buccal features, ontogeny, character variation, Vietnam

\begin{abstract}
The morphology of tadpoles has long received too little attention in taxonomic and phylogenetic contexts, beyond the use of Orton's general tadpole types, despite the potential of larval characters for resolving problems in systematics. A possible explanation for this neglect is the ontogenetic variation of external morphology. In order to understand the value of larval characters in taxonomy and systematics, it is necessary to determine the developmental stage at which characters reach their definitive size, form and colour before meaningful comparisons can be made within and between species. Here I use the tadpole of Rana (Sylvirana) nigrovittata as a model organism to assess ontogenetic character variation. Morphometric measurements were taken, and external oral and internal buccal characters were assessed separately for each developmental stage from 26 to 38 . Coefficients of variation were calculated for each morphometric character at each stage of development to test the character's efficiency in reflecting the morphology of the tadpole. Most morphometric characters taken from the body described the shape of the animal well and varied little among individuals, whereas those taken from the tail were less reliable and those of the oral disk were quite variable due to contraction during fixation. A developmental 'climax' for most characters was reached by specimens between stages 32-40, indicating that they are best suited for morphological intra- and interspecific comparisons.
\end{abstract}

\section{Contents}

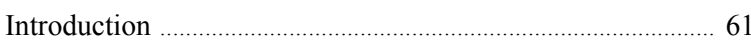

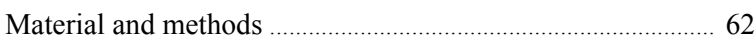

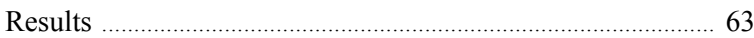

Description of external morphology of tadpole ................ 63

Description of internal buccal features ................................ 66

Character variation during development ............................... 67

Discussion and conclusions .................................................... 70

General morphology and oral disk ....................................... 70

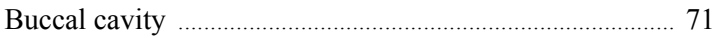

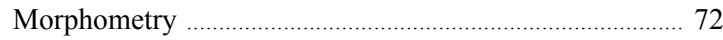

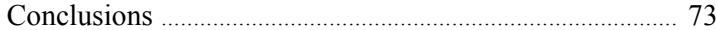

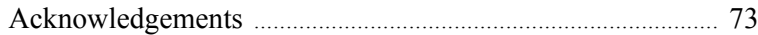

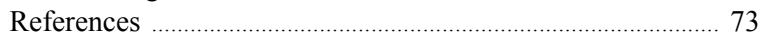

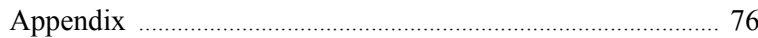

\section{Introduction}

Biodiversity studies of anurans suggest that a great number of new taxa remains to be discovered in this group (Glaw and Köhler, 1998; Glaw et al., 1998). Species complexes, in which individuals are morphologically similar, are of particular interest in this context. In such complexes, data sets other that those scored from adult morphology (e.g. molecular biology, advertisement calls, reproductive biology and ecology, and larval morphology) are often needed to fully resolve taxonomic and systematic issues. Numerous anuran families (e.g. Ranidae) require thorough systematic revision using new approaches. The increasing number of tadpole descriptions and the 'discovery' of new characters (e.g. buccopharyngeal features) proved to be relevant in resolving taxonomic problems (e.g. Wassersug, 1980; Lannoo et al., 1987; Grillitsch et al., 1993; Chou and Lin, 1997; Altig and McDiarmid, 1999a; d'Heursel and de Sá, 1999). The morphology of anuran larvae was thought to be highly adaptive to their environment and thus only poorly reflect phylogenetic relationships between them. However, several recent papers have shown, on the contrary, that tadpole characters contain phylogenetic signals (Haas, 1996, 1997, 2003; Larson and de Sá, 1998; de Sá and Swart, 1999; Maglia et al., 2001). Due to the entirely dif- 
ferent organisation of anuran larvae in comparison with adults, the characters of tadpoles are complementary to those of adults and this set of new characters could help to resolve taxonomic and phylogenetic problems where adult characters alone have been inadequate. Furthermore, the increasingly reliable identification of larval stages, thanks to the DNA bar-coding method, should promote interest in taxonomic descriptions of tadpoles and their use in ecological studies. More generally, the importance of larval stages in biological studies is likely to increase with the availability of new molecular identification methods (Hebert et al., 2004; Thomas et al.,2005; Vences et al., 2005).

The use of tadpole morphology in taxonomic and systematic studies requires full comprehension of the events that punctuate tadpole development, e.g. time of appearance, development, and regression of larval structures. Various authors have used a developmental 'climax' period, on which they based their description of 'mature' tadpoles (e.g. Boulenger, 1897-1898; Wright, 1924; Nichols, 1937; Orton, 1946, 1947; Gosner and Black, 1954, 1957; Gosner, 1959; Inger, 1956; Hampton and Volpe, 1963;

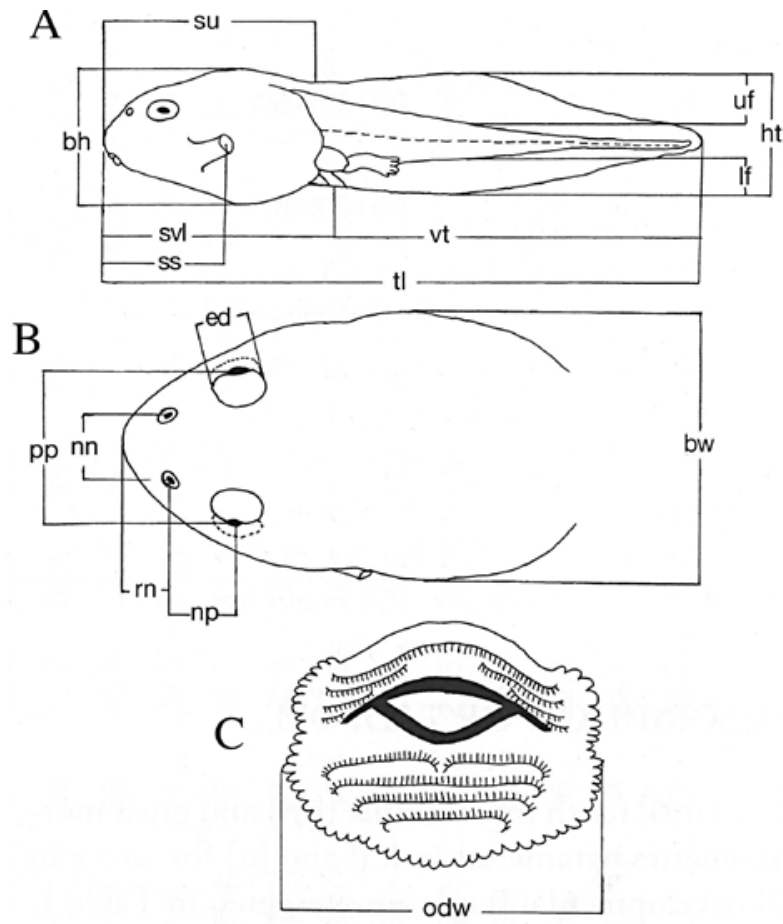

Fig. 1. Schematization of the landmarks used for morphometric measurements. (A) profile; (B) dorsal view; (C) oral disk. For legends see Table 1.
Wassersug and Duellman, 1984; Wassersug, 1989). However, most researchers have not clearly defined the stages of the larval ontogeny corresponding to the 'climax', with the exception of Wassersug (1973), who 'framed' this concept between stages 26-36. In any case, the term 'mature' should be avoided for tadpoles and its use restricted to its proper sense (i.e. attainment of sexual maturity).

A number of previous studies have focused on variations of tadpole characters during development (Nichols, 1937; Bresler and Bragg, 1954; Gosner and Black, 1954; Limbaugh and Volpe, 1957; Gosner and Rossman, 1960; Zweifel, 1961, 1970; Gaudin, 1965; Agarwal and Niazi, 1980; Dutta and Mohanty-Hejmadi, 1984; Tubbs et al., 1993; Hall et al., 1997). Ontogenetic variation has important implications for the use of tadpole characters in taxonomy. For example, should only animals at an identical stage of development be compared? Do the characters continue to vary throughout the larval period, or do they stabilize at a given point of ontogeny? If a developmental 'climax' actually exists, which stages of development does it encompass? Are all the morphometric measurements that can be taken on a tadpole relevant for comparisons?

Herein, I use tadpoles of Rana nigrovittata to assess ontogenetic character variation. This study integrates, for the first time, the variation of the morphological characters commonly used in comparative studies (general colour, oral disk features) with morphometric characters and buccopharyngeal morphology.

\section{Material and methods}

Tadpoles were collected in Ben En National Park, Thanh Hoa Province, Vietnam (19 $30^{\circ}-40^{\prime} \mathrm{N}$, $\left.105^{\circ} 21^{\prime}-35^{\prime} \mathrm{E}\right)$ during July and August 1997 . This National Park is situated in a region of low hills surrounding the Song Muc Lake. Altitude ranges from 20-497 $\mathrm{m}$ above sea level, with most areas being below $200 \mathrm{~m}$. The vegetation is tropical semievergreen forest, partly degraded by human activity. The climate is sub-tropical, with the heaviest rainfall between July and October. Between 1961 and 1990, the average temperature was $28.9^{\circ} \mathrm{C}$ in July and $27.8^{\circ} \mathrm{C}$ in August (Tordoff et al., 1997).

Tadpoles were collected along a small forest stream. 
The stream was about 1-2 $\mathrm{m}$ broad and its depth ranged from a few $\mathrm{cm}$ in fast-flowing parts to $70 \mathrm{~cm}$ in the deepest pools. The bottom consisted of rocks, gravel, and sand covered by dead leaves in the quiet pools. Egg clutches were found in holes (presumably crab holes) on the banks of the stream. These holes were about $10 \mathrm{~cm}$ in diameter with $10-15 \mathrm{~cm}$ depth of stagnant water coming from the stream, without organic matter. The clutches were laid in a single surface layer of numerous small eggs (diameter $=1.6$ $\pm 0.1 \mathrm{~mm}, n=10$; with a jelly capsule of $3.5 \pm 0.3$ $\mathrm{mm}, n=7$ for eggs at stage 4) with a dark brown animal pole and an ivory white vegetal pole. The tadpoles seem to complete their development entirely in this nutrient-poor microhabitat. In captivity, embryos at stage 4 and tadpoles at stage 27 took 41 and 27 days, respectively, to complete metamorphosis. They belonged to the benthic form (type 2 of Altig and Johnston, 1989). Tadpoles were not associated with other species and not found in the free water of the stream (similar observations were made at another site in Northern Vietnam).

Embryos and young tadpoles collected from four clutches (ranging from stages 4-25) were reared in plastic bowls of an average $24 \mathrm{~cm}$ diameter and 10 $\mathrm{cm}$ depth. They were fed with fish food (TetraMin). Some tadpoles were reared through metamorphosis for identification purposes. Tadpoles in developmental stages ranging from 26 to 38 (Gosner, 1960) were preserved in a mixture of equal parts of $4 \%$ formaldehyde and 70\% ethanol (Grillitsch, 1984) in order to obtain a series comprising all developmental stages. Tadpoles are deposited in the collection of the Museum National d'Histoire Naturelle, Paris (MNHN; see list in Appendix 1).

Twenty-two morphological measurements were taken for each tadpole (Fig. 1 and Table 1). Measurements of snout-vent length were taken with a hand calliper, the other measurements with a graduated ocular micrometer in a stereo-microscope (Leica MS 5). Drawings were made with a camera lucida. Eight tadpoles (except for stages 34, 35 and 36, for which only seven, five and seven individuals were available, respectively) were randomly selected for each stage from four different clutches, and measured. Data were analysed with the software package SPSS 10.1 for Windows. In order to express the variation of morphometric parameters, Haldane's coefficient of variation (Delaugerre and Dubois, 1985) (i.e. Pearson's coefficient of variation, as corrected by Haldane, 1955; Sokal and Braumann, 1980) was calculated for each stage and character; subsequently, the mean variation coefficients obtained for each stage within a character were calculated. These calculations were repeated for each character. Although it has been shown that morphometric distances between fresh and preserved specimens change after few months in preservative (Lee, 1982), if all specimens compared spent the same time in preservative, as it is the case in the present study, these morphometric distortions should be similar for all specimens. Preservationinduced distortion is therefore assumed to have been stabilized and to be comparable for all samples.

Morphological terminology follows Altig and McDiarmid (1999b); terminology of oral disk follows Altig (1970); Keratodont Formula follows Dubois (1995); developmental stages were determined according to Gosner (1960); and the terminology of buccopharyngeal cavity features follows Wassersug (1976a).

Preparation for SEM examinations (JEOL JSM 840) comprised ethanol dehydration, critical-point-drying (liquid carbon dioxide), and gold sputter-coating.

\section{Results}

\section{Description of external morphology of tadpole}

The following description is based on two tadpoles at stages 31 (MNHN 1998.7405) and 37 (MNHN 1998.5250). Morphometric data for each stage are presented in Table 1. In dorsal view (Fig. 2A), body oval to pyriform, snout nearly rounded. Eyes moderately large (diameter about 0.1 time body length), bulging, separated by a distance equal to about 1.5 times internarial distance, directed laterally and positioned dorsolaterally, not visible in ventral view. Nares rounded, small, rimmed, directed and positioned anterolaterally, slightly closer to snout than to pupils. In profile (Fig. 2B), body low, snout rounded but flattened on top. Spiracle sinistral, conical, very short but not attached to body wall, positioned laterally (at mid-distance between dorsum and venter) to slightly dorsolaterally, oriented slightly more posteriorly than posterodorsally; spiracular opening oval. Tail musculature moderate, gradually tapering, almost reaching tail tip. Tail fins moderate, not extending 
Table 1. Morphometric data for stages 26-38. Mean \pm SD, Haldane's variation coefficient, number of measurements in parentheses. BH, maximum body height, BW, maximum body width; DPG, length in transversal plan of dorsal papillae gap; ED, maximum eye diameter; HT, maximum tail height; LF, maximum height of lower tail fin; LTR1I, length of medial gap between portions of first tooth row of lower lip; LTR2, length of second tooth row of lower lip; NN, internarial distance; NP, naro-pupillar distance; ODW, oral disk width; PP, interpupillar

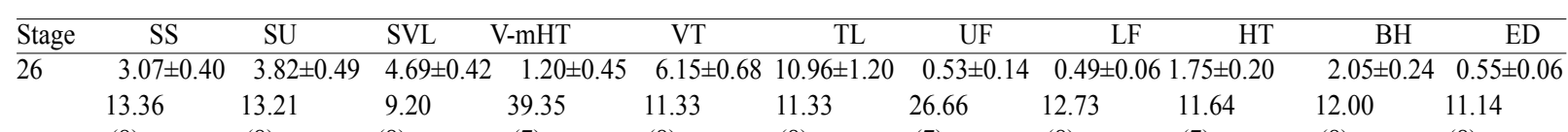

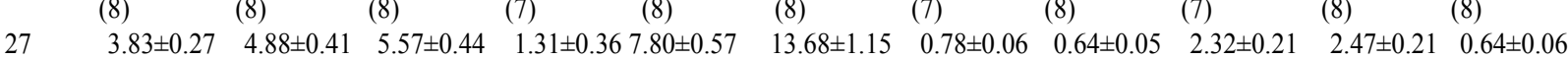
$\begin{array}{lllllllllll}7.19 & 8.75 & 8.13 & 28.20 & 7.56 & 8.71 & 7.18 & 7.53 & 9.50 & 8.90 & 9.45\end{array}$
$(8)$
(8)
(8) (8)
(8)
(8)
(8)
(8)
(8)
(8)
(8)

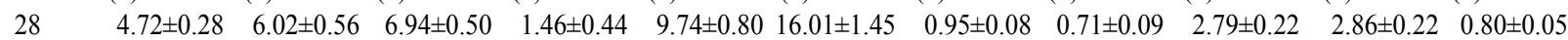
$\begin{array}{lllllllllll}6.07 & 9.52 & 7.38 & 31.09 & 8.46 & 9.37 & 8.19 & 13.13 & 8.26 & 7.84 & 6.97\end{array}$
(8)
(8)
(8)
(8)
(8)
(8)
(7)
(8)
(8)
(8)
(8)

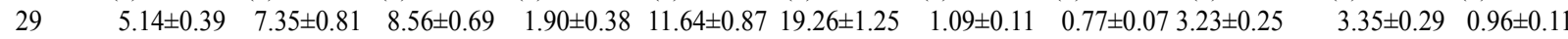
$\begin{array}{lllllllllll}7.95 & 11.37 & 8.36 & 20.62 & 7.71 & 6.73 & 10.77 & 9.77 & 7.84 & 9.03 & 8.20\end{array}$
(8)
(8)
(8) (8)
(7)
(8)
(8)
(8)
(8)
(8)

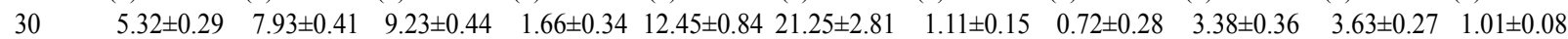
$\begin{array}{lllllllllll}5.67 & 5.32 & 4.87 & 21.07 & 6.94 & 13.64 & 13.58 & 19.47 & 11.01 & 7.53 & 7.60\end{array}$
(8)
(8)
(8)
(8)
(8) (8)
(8) (8)
(8)
(8)
(8)

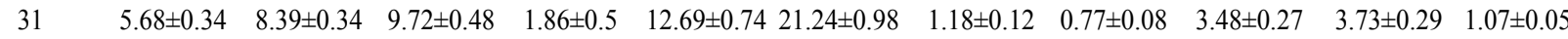
$\begin{array}{lllllllllll}6.23 & 4.12 & 5.14 & 27.97 & 6.04 & 4.77 & 10.34 & 10.85 & 7.97 & 8.14 & 4.79\end{array}$
(8)
(8)
(8)
(8)
(7) (7)
(8)
(8) (8)
(8)
(8)

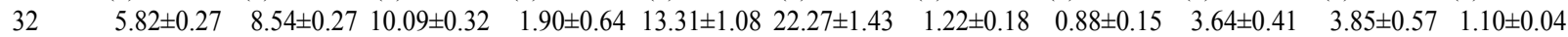
$\begin{array}{lllllllllll}4.85 & 3.23 & 3.23 & 34.85 & 8.40 & 6.64 & 14.87 & 18.18 & 11.57 & 15.25 & 3.47\end{array}$
(8)
(8)
(8)
(8) (8)
(8)
(8)
(8)
(8)
(8)
(8)

$\begin{array}{llllll}6.17 \pm 0.33 & 8.57 \pm 0.42 & 10.39 \pm 0.63 & 2.36 \pm 0.79 & 13.63 \pm 1.01 & 23.04 \pm 1.24\end{array}$
(8)
(8)
(8)
(8)
(8)
(8)
$16.40 \quad 14.73$
(8)

$3.85 \pm 0.46$

$4.15 \pm 0.46 \quad 1.13 \pm 0.07$

$\begin{array}{llllll}6.19 \pm 0.27 & 8.68 \pm 0.50 & 10.53 \pm 0.23 & 2.37 \pm 0.22 & 13.88 \pm 0.54 & 23.15 \pm 0.82\end{array}$ 4.51 5.99

2.33

9.51

4.08

3.71

(8) $\quad(8)$

(8)

(8)

(6)

(6)

(6) (6)

(6) (6)

$5.58 \quad 5.40$

$3.55 \pm 0.11$

3.81

$\begin{array}{llllll}6.68 \pm 0.32 & 9.06 \pm 0.46 & 11.35 \pm 0.83 & 3.51 \pm 1.11 & 14.89 \pm 0.72 & 25.63 \pm 1.43\end{array}$

6) $\quad(6)$

(6) (6)

(6)

2.07

1.69

$4.96 \quad 5.31$

$\begin{array}{lll}7.55 & 32.64 & 4.98\end{array}$

$5.80 \quad 10.46$

8.55

$4.31 \pm 0.33$

(6)

(6)

$\begin{array}{llllll}(7) & (7) & (7) & (7) & (7) & (7) \\ 6.44 \pm 0.36 & 9.00 \pm 0.53 & 11.41 \pm 0.51 & 2.25 \pm 0.60 & 15.34 \pm 0.67 & 25.52 \pm 0.90\end{array}$

7) $\quad(7)$

(7) (7)

(7) (7)

$8.36 \quad 5.35$

36

5.82

6.08

$4.57 \quad 27.65$

4.5

3.64

$1.47 \pm 0.12 \quad 0.99 \pm 0.09$

$4.20 \pm 0.35$

(8)

(8) (8)

(8) (8)

(8)

8.71
$(8)$

9.85

8.59

4.36

$1.26 \pm 0.44$

8) (8) (8)

(8)

(8)

$\begin{array}{llllll}7.01 \pm 0.34 & 10.16 \pm 0.71 & 12.25 \pm 0.71 & 2.30 \pm 0.68 & 16.94 \pm 0.81 & 27.69 \pm 1.36 \\ 5.03 & 7.16 & 5.96 & 30.39 & 4.94 & 5.06\end{array}$

$\begin{array}{llllll}(8) & (8) & (8) & (8) & (8) & (8) \\ 6.87 \pm 0.20 & 9.69 \pm 0.24 & 12.17 \pm 0.16 & 3.32 \pm 1.83 & 16.26 \pm 0.85 & 27.30 \pm 0.86\end{array}$ $8.48 \quad 14.20$

14.20

$4.42 \pm 0.48$

(8) (8)

11.16

4.65

(8)

38

$1.57 \pm 0.08 \quad 1.07 \pm 0.08$

(8) (8)

(8)

$\begin{array}{llllll}3.11 & 2.63 & 1.38 & 57.43 & 5.43 & 3.28\end{array}$

$5.34 \quad 8.07$

3.13

4.63

(8)

$\begin{array}{llllll}(6) & (6) & (6) & (6) & (6) & \text { (6) }\end{array}$

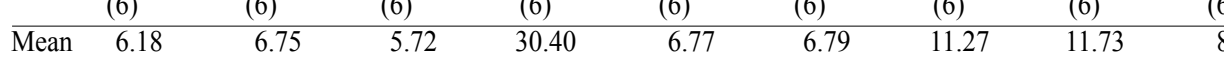

8.79

(6)

7.11 8.99

(6)

onto body; dorsal fin convex, higher than ventral fin which more or less follows tail musculature; point of maximum height of tail located in first third of tail length, tail tip bluntly pointed. Anal tube moderate, dextral, tubular (slightly bulging in the middle), directed posteriorly, linked to ventral tail fin, its opening lateral.

Oral disk (Fig. 2C) anteroventral, emarginated and bordered by a row of five to six short, rounded and massive papillae on each side of upper labium, medial gap of about $1 / 2$ to $2 / 3$ width of oral disk; lower labium with one continuous row of smaller, rounded submarginal papillae and one row of elongate marginal papillae. Keratodont formula 1:1+1/1+1:2. External rows $\left(\mathrm{A}_{1}\right.$ and $\left.\mathrm{P}_{3}\right)$ bearing smaller keratodonts than other rows, $\mathrm{P}_{2}$ longest (in plane projection), 
distance; RN, rostro-narial distance; SS, distance from tip of snout-opening of spiracle; SU, distance from tip of snout-insertion of upper tail fin; SVL, snout-vent length; TL, total length; UF maximum height of upper tail fin; UTR2, length of second tooth row of upper lip; UTR2I, length of medial gap between portions of second tooth row of upper lip; V-mHT, distance from opening of vent-point of maximum tail height; VT, distance from opening of vent-tip of tail. Last line = mean of Haldane's variation coefficient during developmental stages 26-38.

Continued

\begin{tabular}{|c|c|c|c|c|c|c|c|c|c|c|c|}
\hline \multirow{3}{*}{$\frac{\text { Stage }}{26}$} & BW & PP & $\mathrm{NN}$ & $\mathrm{RN}$ & NP & ODW & $\overline{D P G}$ & UKR2 & LKR2 & UKR2I & LKR1I \\
\hline & $2.87 \pm 0$ & $1.52 \pm 0.17$ & $1.09 \pm$ & $0.57 \pm$ & $0.74 \pm$ & $1.23 \pm 0.18$ & $0.81 \pm 0.07$ & $0.73 \pm 0.16$ & $0.80 \pm 0.10$ & $.49 \pm 0.02$ & $0.04 \pm 0.04$ \\
\hline & 10.42 & 11.81 & 7.47 & 14.67 & 18.56 & 14.90 & 8.30 & 23.30 & 13.53 & 4.46 & 93.48 \\
\hline
\end{tabular}

$\begin{array}{lllllllllll}(8) & (8) & (8) & (8) & (8) & (8) & (8) & (5) & (8) & (5) & \text { (8) }\end{array}$

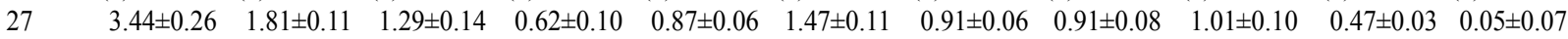
$\begin{array}{lllllllllll}7.89 & 6.22 & 11.47 & 16.22 & 7.87 & 7.66 & 7.19 & 8.85 & 9.81 & 5.64 & 130.6\end{array}$
(8)
(8)
(8)
(8)
(8) $\quad$ (8)
(8)
(7)
(8)
(7)
(8)

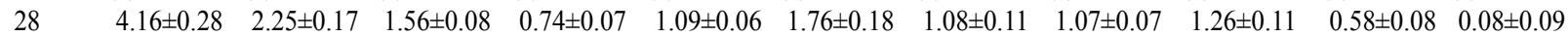
$\begin{array}{lllllllllll}6.90 & 7.80 & 5.44 & 9.52 & 5.74 & 10.53 & 10.35 & 6.49 & 8.79 & 13.83 & 105.3\end{array}$
(8)
(8)
(8)
(8)
(8) $\quad(8)$
(8)
(8)
(8)
(8)
(8)

11.65

$1.28 \pm 0.06$

$1.53 \pm 0.11$

$0.63 \pm 0.07 \quad 0.02$
10.16
4.76
6.26
(8)
(8)
(8) (8)
(8)
(8)
(8)
(8)
(8)
(8)
(8)

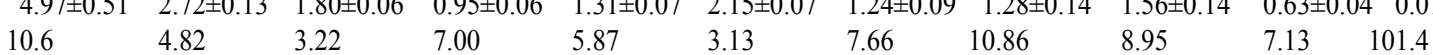
(8)
(8)
(8)
(8) $\quad(8)$
(8) (8)
(8)
(8)
(8)
(8)

$\begin{array}{llll}2.21 \pm 0.14 & 1.26 \pm 0.14 & 1.29 \pm 0.19 & 1.63 \pm 0.12\end{array}$

$0.64 \pm 0.04 \quad 0.02 \pm 0.02$

(8)

(8)

(8)

10.90

5.82
$(8)$

(8)

(8)

(8)

7.55

$6.45 \quad 114.6$

$\begin{array}{ll}5.35 \pm 0.62 & 3.00 \pm 0.1 \\ 11.88 & 4.00\end{array}$

$\begin{array}{ll}.88 \pm 0.10 & 1.04 \pm 0.12 \\ 50 & 11.42\end{array}$

$2 \quad 1.39 \pm 0.10$

(8) (8) (8)

(8)

(8)

(8)

$\begin{array}{lllllllllll}11.88 & 4.00 & 5.50 & 11.42 & 7.71 & 5.63 & 6.28 & 9.85 & 8.75 & 11.42 & 151.2\end{array}$
(8)
(8)
(8)
(8)
(8) (8)
(8)
(8)
(8)
(8)
(8)

$\begin{array}{clllllllllll}33 & 5.62 \pm 0.63 & 3.06 \pm 0.12 & 1.96 \pm 0.08 & 1.10 \pm 0.13 & 1.46 \pm 0.10 & 2.39 \pm 0.18 & 1.45 \pm 0.06 & 1.46 \pm 0.19 & 1.77 \pm 0.12 & 0.64 \pm 0.08 & 0.008 \pm 0.39 \\ & 11.59 & 3.89 & 4.04 & 12.41 & 6.84 & 7.86 & 4.36 & 13.40 & 7.08 & 12.39 & 155.9\end{array}$
(8)
(8)
(8)
(8)
(8) (8)
(8) (8)
(8)
(8)
(8)
(8)

$1.72 \pm 0.14$

0.68

$02 \quad 0.009 \pm 0.006$
(6)
(6)
(6)
(6)
(6) (6)

(6)

(5)

(6)

(5)

(6) $\begin{array}{lllllllllll}6.85 & 4.98 & 2.93 & 9.17 & 6.46 & 9.03 & 7.93 & 11.48 & 12.61 & 14.81 & 274.0\end{array}$
(7)
(7)
(7)
(7)
(7)
(7)
(7)
(7)
(7)
(7) (7)

(7)
$0.006 \pm 0.007$

$9.16 \quad 3$. $3.22 \quad 10.49$

$5.22 \quad 4.28$

8.87

8.87
$(8)$

(8)

(8) $\quad(8)$

(8) (8)

5.86
$(8)$

$13.92 \quad 121.9$

$\begin{array}{lllll}6.47 \pm 0.69 & 3.55 \pm 0.16 & 2.09 \pm 0.09 & 1.11 \pm 0.10 & 1.71 \pm 0.09\end{array}$ $11.04 \quad 4.62$ 4.30 $9.30 \quad 5.62$ 9.06 6.18

$\begin{array}{lllllllllll}(8) & (8) & (8) & (8) & (8) & (8) & (8) & (7) & (8) & (7) & (8) \\ 6.28 \pm 0.21 & 3.58 \pm 0.10 & 2.07 \pm 0.07 & 1.18 \pm 0.10 & 1.73 \pm 0.04 & 2.65 \pm 0.16 & 1.50 \pm 0.08 & 1.79 \pm 0.08 & 2.00 \pm 0.17 & 0.69 \pm 0.10 & 0.004 \pm\end{array}$ 5.29

$2.03 \pm 0.20$

(8)

(8)

$\begin{array}{llllllllllll}38 & 6.28 \pm 0.21 & 3.58 \pm 0.10 & 2.07 \pm 0.07 & 1.18 \pm 0.10 & 1.73 \pm 0.04 & 2.65 \pm 0.16 & 1.50 \pm 0.08 & 1.79 \pm 0.08 & 2.00 \pm 0.17 & 0.69 \pm 0.10 & 0.004 \pm \\ & 3.56 & 2.98 & 3.31 & 9.08 & 2.19 & 6.25 & 5.52 & 4.45 & 9.08 & 15.37 & 174.3\end{array}$ $\begin{array}{llllllllll}(6) & (6) & (6) & (6) & (6) & (6) & (6) & (6) & (6) & (6)\end{array}$

\begin{tabular}{|c|c|c|c|c|c|c|c|c|c|c|c|}
\hline$\overline{\text { Mean }}$ & 8.33 & 5.30 & 4.76 & 10.67 & 6.75 & 7.35 & 8.04 & 9.53 & 9.13 & 10.55 & 154.01 \\
\hline
\end{tabular}

$\mathrm{A}_{2}$ shortest, restricted to lateral portions of anterior labium, $\mathrm{P}_{1}$ with a short medial gap. Keratodonts (Fig. 3) stocky (about $30 \mu \mathrm{m}$ long) with a curved spatulate apical portion bearing 10-12 blunt marginal denticles. Jaw sheaths slightly serrated, white with a fine black halo along serrations, upper beak nearly inverted U-shaped, lower beak V-shaped.

Four pairs of glands, better visible at the end of development than at the beginning, lying under the skin, with numerous white pores. One pair of large rounded glands on the upper part of the flanks, halfway between insertion of tail and eye. Another pair of small oval glands at the end of body, just in front of tail, at the apex of caudal myotomes level (the posterior glands); a third pair of large oval glands at the same level, but under body (posteroventral 

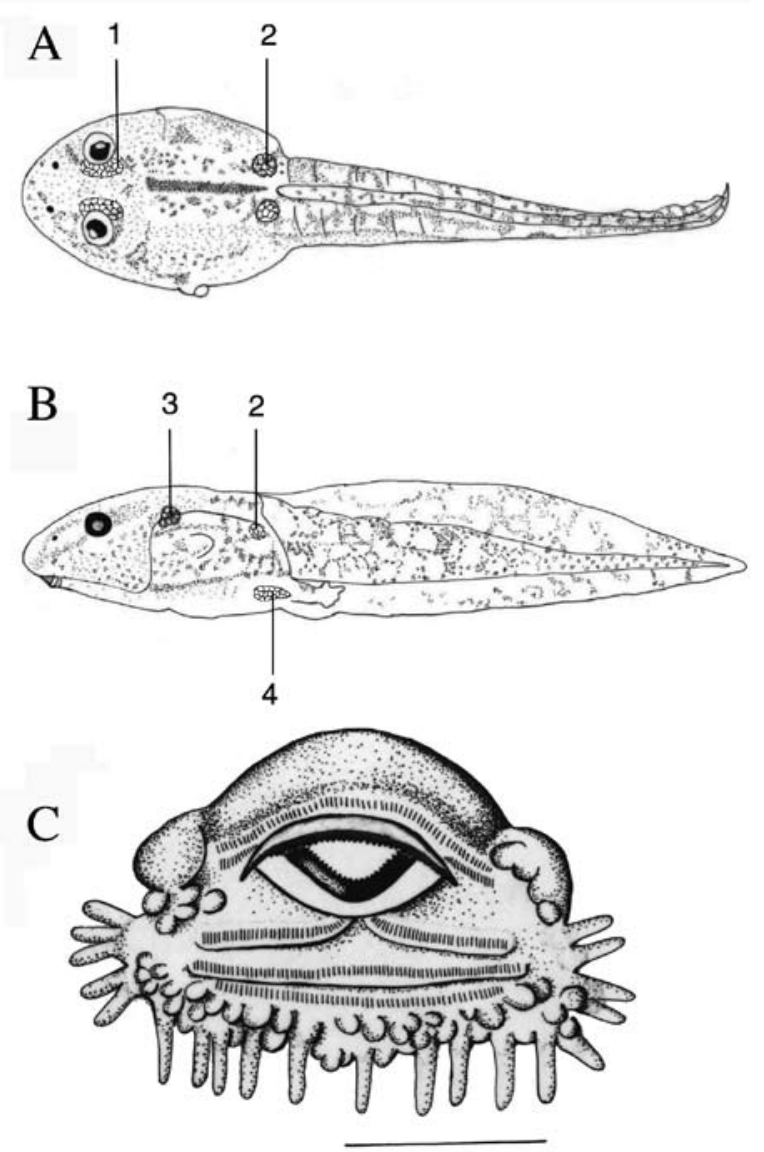

Fig. 2. Tadpole of Rana nigrovittata (MNHN 1998.5952, stage 35, SVL $11.5 \mathrm{~mm}$ and TL $25.9 \mathrm{~mm}$ ). (A) dorsal view; (B) profile; (C) oral disk. Scale bar $=1 \mathrm{~mm} .1$ = interorbital gland; $2=$ posterior gland; 3 = upper flank gland; 4 = posteroventral gland.

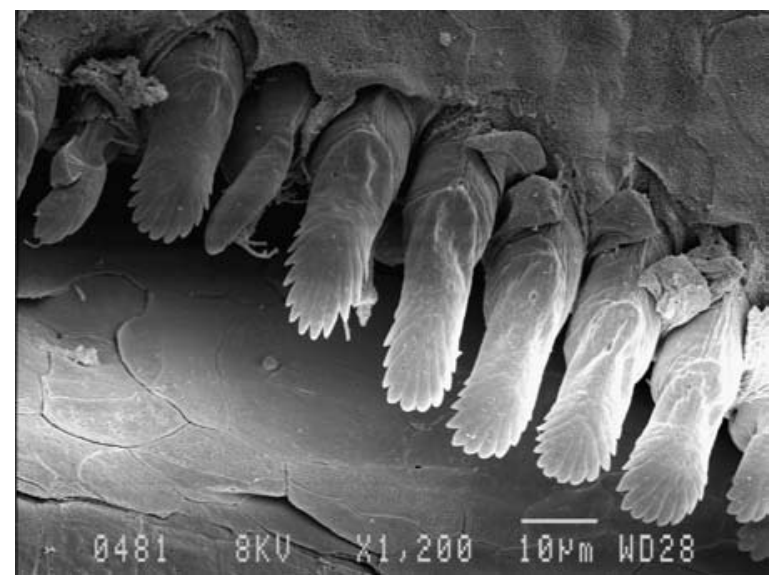

Fig. 3. Keratodonts of row $\mathrm{P}_{1}$ of the tadpole of Rana nigrovittata (MNHN 1998.5212, stage 36, SVL $11.3 \mathrm{~mm}$ and TL 25.7 $\mathrm{mm})$. glands). The fourth pair between the eyes, against their inner side, crescent-shaped (the interorbital glands). No neuromasts visible.

Preserved specimens, dorsum grey-khaki with a dark grey stripe between eyes and on snout. A large grey-khaki stripe above each eye, like a brow. Throat and chest strongly mottled with grey-khaki. Belly whitish-transparent, as the thigh underneath. Hindlimb whitish, its upper part strongly coloured, dark grey. Caudal muscles white and tail fins translucent, mottled with grey-khaki. Top of papillae dark-grey.

\section{Description of internal buccal features}

The description is based on a single tadpole in stage 36 (MNHN 1998.5212).

Buccal floor (Fig. 4A): Prelingual arena concave with four papillae just in front of infralabial papillae and few pustules scattered on the internal wall of lower jaw; a pustulose knob at the level of lower jaw corner. Two massive spoon-shaped infralabial papillae, marginally pustulose, located at each posterolateral corner. Tongue anlage round, a few prominent, with two long lingual papillae in a transverse row and a smaller one on same alignment on right side (most certainly an artefact, the true arrangement being two long papillae in central position and one small on each side in a transversal line). Buccal floor arena oval, defined by two or three stout papillae on each side, most curving anteromedially, the two longest on each side in front of the buccal pocket; anterior part of arena occupied by a short groove, all the rest with about 25 pustules uniformly distributed. Buccal pockets transverse to anterolateral, closer to tongue anlage than to medial end of ventral velum; about 20 prepocket papillae; a few pustules arranged in an arc of a circle posteriorly bordering the buccal roof arena from one buccal pocket to the other. About 15 low pustules medially before ventral velum. Ventral velum continuous, wavy, with spicular support; lacking distinct medial notch, glottis visible; margin with ten projections, the six medial ones closer together; margin and projections with secretory pits. Branchial baskets oblique, wider than long; three gill chambers on each side; filter ruffles with tertiary folds.

Buccal roof (Fig. 4B): Prenarial arena rectangular with a transversal prenarial ridge with pustulose edge, flanked with two large pustules in an anterola- 
teral alignment and a single large pustule in the centre of prenarial arena. Prenarial papillae present, short and pustulose, rising in the middle of anterior narial wall. Choanae narrow, transverse and elongate. Narial valve a thin flap without projections. Postnarial papillae long, transversally to anteromedially directed, distal third narrow, three pustules on each just before the narrowing and about two pustules at tip. Postnarial arena with about five pustules. Medial ridge truncate, triangular, wider than high, densely serrated on central part of margin. Lateral ridge papillae absent. Buccal roof arena elliptical,
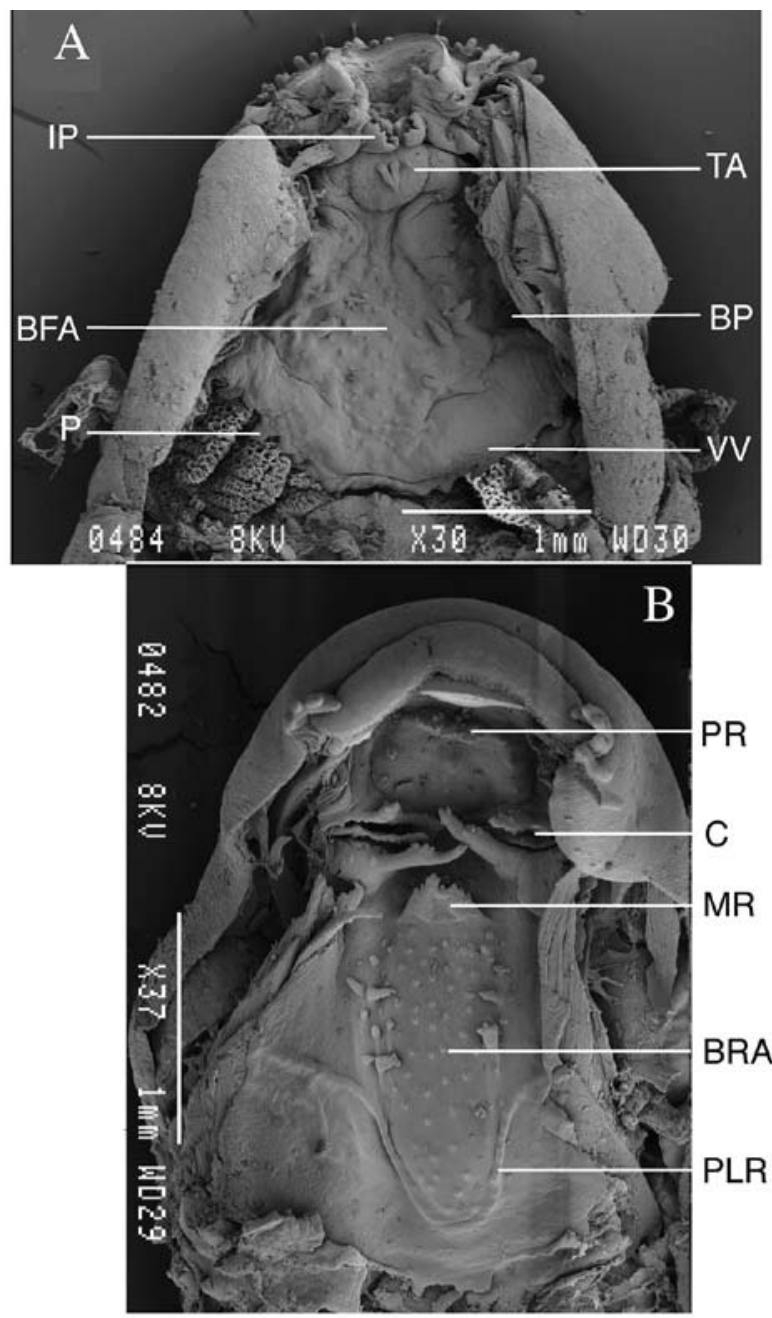

Fig. 4. Buccal cavity of the tadpole of Rana nigrovittata (MNHN 1998.5212, stage 36). (A) buccal floor; (B) buccal roof. BFA = buccal floor arena; $\mathrm{BP}=$ buccal pocket; $\mathrm{BRA}=$ buccal roof arena; $\mathrm{C}=$ choana; $\mathrm{IP}=$ infralabial papilla; $\mathrm{MR}=$ medial ridge; $\mathrm{P}=$ projections of the ventral velum; $\mathrm{PLR}=$ posterolateral ridge; $\mathrm{PR}=$ prenarial ridge $\mathrm{TA}=$ tongue anlage $\mathrm{VV}=$ ventral velum . almost twice as long as wide, posterior end narrowest, defined by two or three buccal roof arena papillae on each side of anterior part of buccal roof arena, the anterior two simple, the most posterior one flattened, pustulose at tip; interior of arena with 60-70 pustules. Posterolateral ridge long, beginning far on the side of buccal roof, U-shaped at posterior end, continuous medially, with dense pustules; a cluster of two to three small papillae at each lateral end (not seen on the figure). Glandular zone across the roof, secretory pits visible laterally. Dorsal velum continuous, medial portion stretching slightly backward towards oesophagus.

\section{Character variation during development}

Mouthparts (Figs. 5A-B): Papillae: Tadpoles at the earliest stages examined (stages 26 and 27) have three papillae on the lateral corner of each labium. The upper labium does not possess other papillae, while the lower labium already possesses two rows of marginal papillae. Tadpoles at stage 28 possess three to five papillae, with a dominant frequency of three. At stage 29, the tadpoles have four to seven papillae on the lateral corner of each labium, most commonly five, and six for the next stages. Submarginal papillae on the lower labium increase in number and size until stage 30 , whereas the marginal papillae continue to increase proportionally to growth until stage 36 . At this late stage, the largest ones are five times larger than the submarginal papillae.

Keratodont formula and keratodonts: At stages 26 to 28 keratodonts are poorly developed, especially in rows $\mathrm{A}_{2}, \mathrm{P}_{1}$, and $\mathrm{P}_{3}$. These early keratodonts are light-brown or yellow-orange and many are not yet formed. The two upper rows of keratodonts $\left(\mathrm{A}_{1}\right.$ and $A_{2}$ ) are of equal length; the same is observed for the two internal rows of the lower lip ( $\mathrm{P}_{1}$ and $\left.\mathrm{P}_{2}\right)$ which are longer that the third one $\left(\mathrm{P}_{3}\right)$. From stage 29 on, keratodonts are fully developed, and darkbrown. From stage 32 on, the keratodont rows have their definitive relative proportions and a density of about 80 keratodonts per $\mathrm{mm}^{2}$.

At stage 26, five of the eight studied specimens have a keratodont formula of $1: 1+1 / 1+1: 2$, one specimen has $1 / 1+1: 1$, and two have $1 / 1+1: 2$. By stage 27 , all specimens possess all ridges, and malformations are found occasionally, such as divisions 
in normally unbroken rows of keratodonts.

Jaw sheath coloration: At the first stages (stages 26 to 28), the jaw sheaths are entirely white except for the serrations, which are black and edged by a fine brown halo. From then until the end of the larval period, the coloration extends during development, linked to the keratinization of sheaths, but does not pass the upper half of the jaw sheath. The basal part stays white. The coloration of the upper beak is more extensive than that of the lower beak. Tadpoles in advanced stages may still show light coloration. In one clutch, most of the tadpoles have the medial third of upper beak poked, sometimes without serration. This abnormality become less marked at the stages $32-33$, but the missing serrations never reappear.

Glands: The pair of glands on the flanks appears early, at stage 28 . At stage 30 , the glands between the eyes and the ventral glands appear which at this stage of development have a more or less central position. From stage 31 onwards, all pairs of glands are present.

Coloration: From stage 28 onwards, coloration of the body is identical to that of a tadpole in stage 36 . However, the tail is still less pigmented, though the pattern is already noticeable. From stage 30 onwards, the coloration of the tadpole is identical to that of a stage 36 tadpole.

Internal buccal features: This description is based on two tadpoles at stage 26 (MNHN 1998.7103 and MNHN 1998.7129), one tadpole at stage 29 (MNHN 1998.5948) and one tadpole at stage 31 (MNHN 1998.7380).

Buccal floor: Prelingual area papillae and pustules are present from stage 26. The tongue anlage is poorly delimited at stage 26 , although lingual papillae are already present; at stages 29 and 31 the tongue anlage is elongate, whereas it is round and better defined at stage 36 . At stage 26, the buccal floor arena papillae are already present, although less developed than at stage 36 ; at stage 29 the size of the BFA papillae approaches that in stage 36 . Less than 10 pustules are present within the arena at stage 26 , while at stage 29 the number of pustules is identical to that observed at stage 36 . Buccal pockets visible at stage 25 . Only a few prepocket pustules are present at stage 26 , while their definitive number is fixed by stage 29 . Only the three lateralmost pairs of projections are present on the ventral velum at stage 26 ;
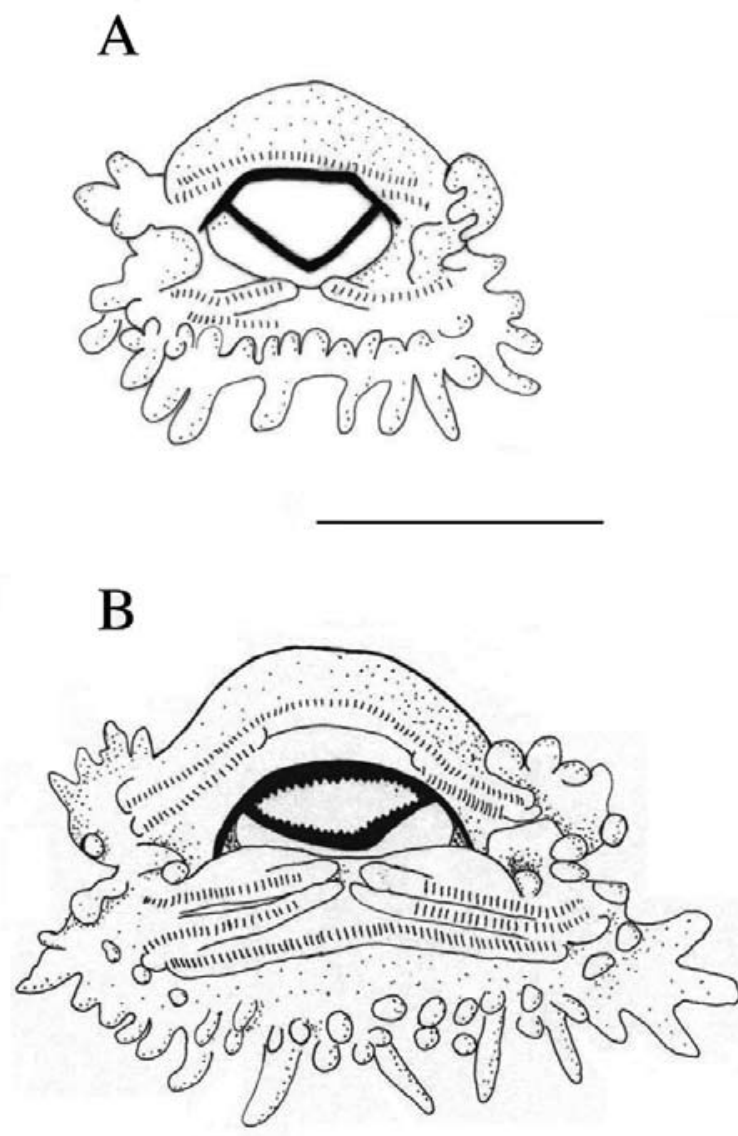

Fig. 5. Oral disk of the tadpole of Rana nigrovittata. (A) at stage 26 (MNHN 1998.7119); (B) at stage 29 (MNHN 1998.7179). Scale bar $=1 \mathrm{~mm}$.

their definitive number is reached at stage 31 .

Buccal roof: The tadpole at stage 26 already has a well-developed prenarial ridge, whereas the number and location of pustules within the prelingual arena seem to vary between individuals, independently of stage. The narial valves and their ornamentations are fully developed from stage 26 onwards. The postnarial papillae are well developed and already pustulose at stage 26 , but they attain their typical form between stages 29 and 31 . At least four small pustules are present in the postnarial arena at stage 26, growing until stage 36 when they reach their full size. The medial ridge is present but it has not reached its maximum size and lacks most of its pustulations on margin at stage 26; from stage 29 onwards it is similar to that of stage 36 . The buccal roof arena is defined by one or two small buccal roof arena papil- 
Table 2. Regression equations, Pearson correlation between total length and parameters (r) and stage and parameters ( $\mathrm{r}$ '), and mean coefficient of variation (range in parentheses). All correlation coefficients are significant at the 0.05 level (2-tailed).

\begin{tabular}{|c|c|c|c|c|}
\hline Morphometric measurements & Equation & $\mathrm{r}$ & r' & Coefficient of variation \\
\hline \multicolumn{5}{|l|}{ Body measurements } \\
\hline Maximum body height (BH) & $Y=0.343 x+0.157$ & 0.957 & 0.885 & $9.0(2.07-15.25)$ \\
\hline Maximum body width (BW) & $Y=0.649 x+0.210$ & 0.953 & 0.873 & $8.3(2.64-11.88)$ \\
\hline Maximum eye diameter (ED) & $Y=0.052 x+0.047$ & 0.952 & 0.939 & $6.1(1.69-11.14)$ \\
\hline Internarial distance $(\mathrm{NN})$ & $Y=0.544 x+0.059$ & 0.960 & 0.879 & $4.8(2.93-11.47)$ \\
\hline Naro-pupillar distance (NP) & $Y=0.128 x+0.057$ & 0.970 & 0.925 & $6.8(2.19-18.56)$ \\
\hline Interpupillar distance (PP) & $Y=0.290 x+0.119$ & 0.971 & 0.933 & $5.3(2.98-11.81)$ \\
\hline Rostro-narial distance (RN) & $Y=0.158 x+0.038$ & 0.881 & 0.843 & $10.7(7.00-16.22)$ \\
\hline Distance snout-opening of spiracle (SS) & $Y=0.868 x+0.222$ & 0.968 & 0.917 & $6.2(3.11-13.36)$ \\
\hline Distance snout-upper tail fin (SU) & $Y=0.394 x+0.350$ & 0.959 & 0.888 & $6.7(2.63-13.21)$ \\
\hline Snout-vent length (SVL) & $Y=0.453 x-0.195$ & 0.979 & 0.934 & $5.7(1.38-9.20)$ \\
\hline Total length (TL) & $-/ /-$ & $-/ /-$ & 0.929 & $6.8(3.28-13.64)$ \\
\hline \multicolumn{5}{|l|}{ Oral disk measurements } \\
\hline Length of dorsal papillae gap (DPG) & $Y=0.387 x+0.042$ & 0.891 & 0.850 & $8.0(4.36-11.65)$ \\
\hline Length of medial gap of P1 (LKR1I) & $Y=0.099 x-0.004$ & -0.460 & -0.437 & $10.6(67.20-291.70)$ \\
\hline Length of P2 (LKR2) & $Y=0.089 x+0.071$ & 0.939 & 0.877 & $9.1(5.86-13.53)$ \\
\hline Oral disk width (ODW) & $Y=0.379 x+0.084$ & 0.949 & 0.893 & $7.3(3.13-14.90)$ \\
\hline Length of A2 (UKR2) & $Y=0.047 x+0.062$ & 0.928 & 0.901 & $9.5(3.44-23.30)$ \\
\hline Length of medial gap of A2 (UKR2I) & $Y=0.304 x+0.016$ & 0.727 & 0.633 & $154.0(3.23-17.17)$ \\
\hline \multicolumn{5}{|l|}{ Tail measurements } \\
\hline Maximum tail height (HT) & $Y=0.130 x+0.158$ & 0.957 & 0.885 & $8.8(3.13-12.34)$ \\
\hline Maximum height of lower tail fin (LF) & $Y=0.150 x+0.033$ & 0.873 & 0.814 & $11.7(5.40-19.47)$ \\
\hline Maximum height of upper tail fin (UF) & $Y=0.054 x+0.059$ & 0.938 & 0.885 & $11.3(5.34-26.66)$ \\
\hline Distance vent-maximum tail height (V-mHT) & $Y=-0.095 x+0.102$ & 0.554 & 0.580 & $30.4(9.51-57.43)$ \\
\hline Distance opening of vent-tip of tail (VT) & $Y=-0.247 x+0.606$ & 0.982 & 0.930 & $6.8(4.08-11.33)$ \\
\hline
\end{tabular}

lae at stage 26 and by two or three fully developed buccal roof papillae by stage 29 . The arena is short, less extended backwards than in oldest stages, growing regularly, continuing to increase after stage 31 , interior with $30-40$ pustules at stage 26,50 pustules at stage 29 and about 60 at stage 31 . The posterolateral ridges are well developed from stage 26 . The glandular zone is present from early stages onwards. An individual at stage 29 already possesses all features of a stage 36 tadpole, but is merely less developed.

Morphometric variation: When plotting measurements as a function of the developmental stage (Figs. 6A-C), all the graphs show an increasingly inflected curve, except for the gap of the first keratodont row of the lower lip (LKR1I), which shows the opposite trend (Fig. 6C). Size increase in all variables is therefore fast in early stages (until stage 32 ) and slows down in late stages. The different developmental tadpole stages (Gosner, 1960) do not have an identical duration (Gollmann, 1991). The early stages extend over longer periods of time, thus the tadpole grows significantly during this period. On the con- trary, later stages based on hindlimb development take place rapidly; the growth of tadpole within each stage is therefore reduced and a lower variation in the values of morphometric parameters is observed. In the case of the gap of the first keratodont row of the lower lip, the values decrease during the development until stage 30 and then stabilize, which confirms that the keratodont rows grow in the early stages and become stabilized at about stage 30 . Nevertheless, the correlation between stages and all parameters is significant (Table 2).

Plotting the measurements as a function of tadpole total size (TL), the growth in each parameter is proportional to the total growth of the tadpole (Figs. 7AC). Morphometric parameters were better correlated to total length than to stages (Table 2). The range of extreme values of the coefficient of variation can be great within a parameter (e.g. 9.51-57.43 in V-mHT). Overall, the characters are highly variable in stage 26 and most stable in stage 38 . The mean coefficient of variation for each character is given in Table 1. Only a few parameters are very variable (thus unreliable) in the constancy of their values (mean value of their 

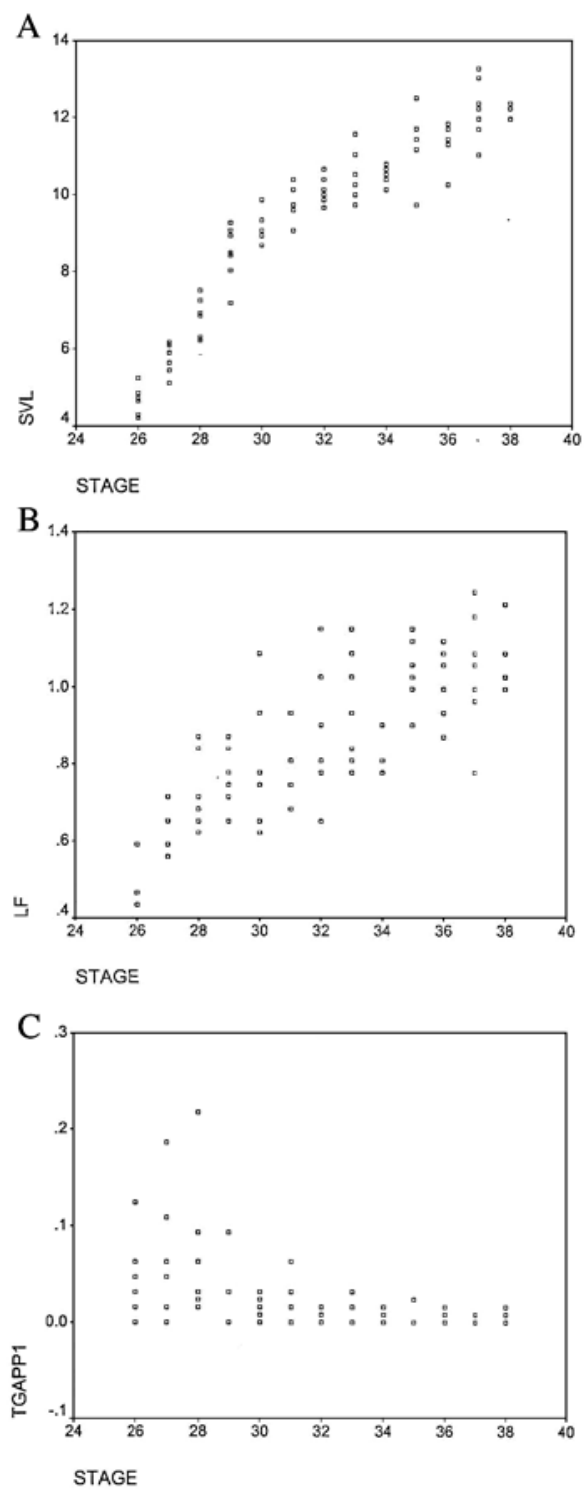

Fig. 6. Correlation between three morphometric parameters and stages. (A) snout-vent length (SVL); (B) lower tail fin (LF); (C) length of the medial gap between portions of first tooth row of lower lip (LTR1I)

coefficient of variation higher than 10), viz. V-mHT, UF, LF, RN, UKR2I and LKR1I. All other characters have a mean coefficient of variation lower than 10 . Among these characters, 10 have a mean coefficient of variation lower than 8 (SS, SU, SVL, VT, TL, ED, PP, NN, NP, ODW) and six have a mean coefficient of variation of 8-10 (BH, BW, HT, DPG, LKR2 and UKR2).

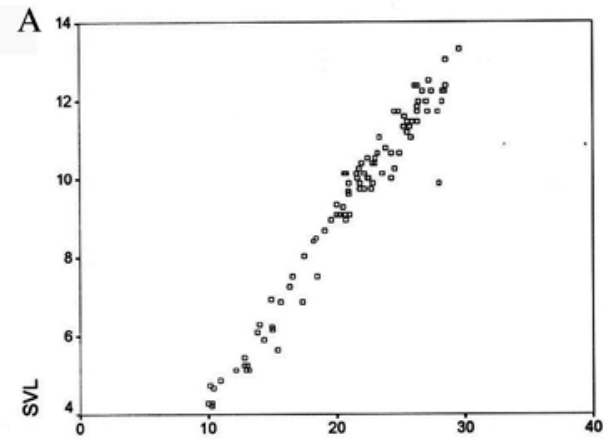

TL

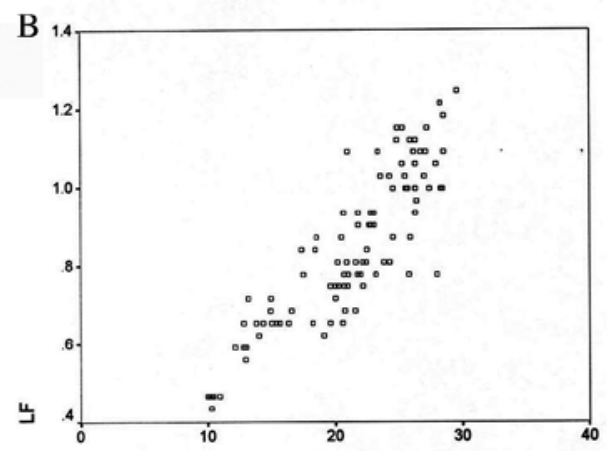

TL

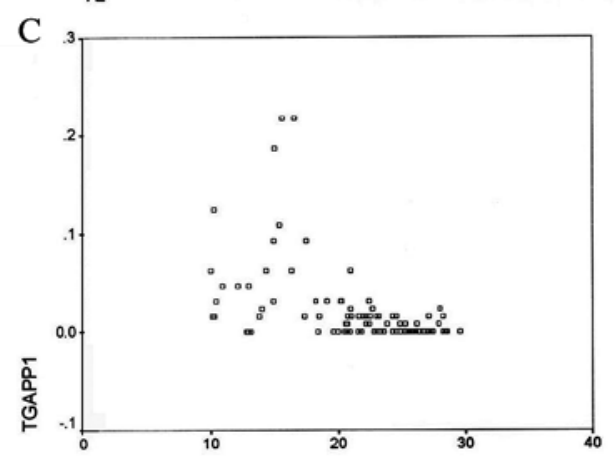

$\mathrm{TL}$

Fig. 7. Correlation between three morphometric parameters and total length (TL). (A) snout-vent length (SVL); (B) lower tail fin (LF); (C) length of the medial gap between portions of first tooth row of lower lip (LTR1I).

\section{Discussion and conclusions}

\section{General morphology and oral disk}

Certain qualitative characters of the external morphology of $R$. nigrovittata tadpoles show variation during tadpole ontogeny.

In most species with a low number of keratodont 
rows (e.g. 2/3), the final number of rows is reached at stage 25 (Gosner and Black, 1954; Limbaugh and Volpe, 1957; Sedra and Michael, 1961), 26 (Zweifel, 1961) or immediately after (this paper). However, in species with a higher number of rows, their number increases longer during ontogeny and shows more variation (Gosner and Black, 1954; Volpe and Harvey, 1958; Dutta and Mohanty-Hejmadi, 1984; Brown, 1989; Hall et al., 1997), even if a certain stability of the keratodont formulae is observed by stage 33 (Grosjean, 2001). Complete mouthparts (i.e. keratodont rows with the maximum density of keratodonts and maximum number of marginal papillae) are present between stages 29-40 in Bufo valliceps (Limbaugh and Volpe, 1957), stage 30 in Rana sevosa (Volpe, 1957) or even earlier in some American hylids (Gaudin, 1965). Zweifel (1961) observed in Hyla wrightorum a continued increase of number and size of marginal papillae until degeneration associated with metamorphosis. The jaw sheath keratization reaches its fully developed state at stage 31 in Spea intermontana (Hall et al., 1997, see also Kaung, 1975). With the beginning of metamorphosis, oral characters become unusable from stage 40 (Gosner, 1960; Zweifel, 1961) or 41 (Sedra and Michael, 1961; Tubbs et al., 1993). The rate of development of the coloration is more variable: the pattern of coloration is evident between stages 29-40 in Rana sevosa (Volpe, 1957); in Bufo valliceps the pigment pattern of the tail is characteristic from stage 32 (Limbaugh and Volpe, 1957); in the Bufo debilis group (Zweifel, 1970) and in Hyla calthula (Ustach et al., 2000) the density of pigments increases at least until stage 36 and even until stage 39 in members of the Rana pipiens complex (Scott and Jennings, 1985). The increase of maculation on the tail and tail-fin during ontogenesis seems to be a fairly general property of tadpoles of the Salientia [e.g. in Rana pipiens (Volpe, 1955), Rana palmipes (Volpe and Harvey, 1958), Hyla avivoca (Volpe et al., 1961), Bombina bombina and B. variegata (Michlowski, 1966), Scaphiopus intermontanus (Hall et al., 1997)]. I am not aware of any studies of the development of macroglands in other species. Gosner (1960) concluded from his observation of several anuran families that the period between stages 30 and 40 is "one of relative stability in key traits" for external morphology and coloration pattern.

\section{Buccal cavity}

The observations on early larval stages (26-31) show that the main morphological characters in the buccal cavity are present from stage 26, although the number and the size of papillae and pustules continues to increase during the following stages. From stage 29 on, all features are present except for the full number of projections of the ventral velum (stage 31). The secretory orifices of the dorsal velum are still not visible at stage 31 . The shape of the tongue anlage varies through the larval period in Rana catesbeiana (Hammerman, 1969). In Pseudacris regilla an earlier stage of stabilization of the characters has been observed (Wassersug, 1976b). Numerous characters on the buccal floor become stabilized by stage 26 (some of them from stage 25): infralabial papillae, lingual papillae, buccal floor arena papillae and the ventral velum projections. True prepocket papillae only appear at stage 29 . Two characters continued changing throughout the larval period: the shape of the tongue varied in a continuous and uniform way until reaching its definitive shape (a typical adult tongue), and the number of pustules within the buccal roof arena increased from stages 25-40. Within the buccal roof, characters were more variable during ontogeny, although most were present from stage 26: in the prenarial papillae, only pustulations were present in stages 25-26, the papillae appearing later; narial valves projections were poorly developed in stages 25-26 and increased afterwards; the ventral edge and pustulation of the medial ridge increased from stages 26-38, and then decreased; the number of pustulations within the buccal roof arena increased from stages 25-34. Other characters were present early (by stage 26), but their size increased during development: postnarial papillae and buccal roof arena papillae (definitive number reached by stage 28). Presence and number of prenarial and postnarial arena pustulations did not seem be correlated with the stage of development. Another study on ontogenetic changes in Central European anuran larvae (genera Bufo, Alytes, Bombina, Pelobates and Rana) lead to roughly the same conclusions (Viertel, 1982). Almost all structures of the buccal cavity are fully differentiated between stages 28 and 32 and begin to degenerate at stage 40 . The most important difference to the present study is the appearance of the 
second pair of lingual papillae between stages 25-28 in Bufo bufo.

Wassersug (1976b) concluded that the buccal cavity of the tadpole of Pseudacris regilla reaches its full development between stages 26-39. In $R$. nigrovittata the stability period for these characters begins at stage 31 , whereas it is from stage 32 for Central European anuran tadpoles (Viertel, 1982). However certain features, such as the tongue anlage shape, and the number and shape of pustulations of large papillae, should be avoided in interspecific comparisons of tadpoles at different developmental stages because of their continuous variation throughout the larval period, showing a different state at each developmental stage.

\section{Morphometry}

Morphometric tadpole characters are widely used in interspecific comparisons and are usually expressed as ratios of total length or snout-vent length. However, they are often employed without knowledge of their intraspecific or intrapopulational variability. Only total length, body length or tail length are usually plotted as functions of developmental stage or total length.

In this study, the measurements of the body of the animals (SS, SU, SVL, VT, TL, ED, PP, NN, NP and ODW) proved to be well correlated with the total length (Table 2). BH and BW were less strongly correlated to the total length, being mainly influenced by the availability of food (pers. obs.). Great differences can be seen between well-fed and poorlyfed tadpoles. Likewise, differences can be obtained if the gut content begin to rot in the dead animal before fixation. The relative variation found in the $\mathrm{RN}$ measurements can likely be explained by the state of contraction of the upper lip (the opening or closing of the oral disk); that observed in the DPG measurements resulted from different arrangements of papillae bordering the gap. The tail characters, especially those taking into account the fins, are very variable between individuals. The morphometric characters of the oral disk are variable in a relatively small array, also depending on the opening or closing (state of contraction) of the labia. The values of LKR1I (tooth gap of the innermost keratodont row of the lower labium) show a great variation among tadpoles less than $20 \mathrm{~mm}$ in length and thus the coefficient of variation reaches high values (67.2-291.7). In the measurements of such tiny distances (here comprised between 0.0 and $0.3 \mathrm{~mm}$ ), the error resulting from inaccuracy of measurement can be as great as the distance itself (Delaugerre and Dubois, 1985). Characters with tiny values in general should therefore be expressed by a range of variation rather than by direct measurements.

Strauss and Altig (1992) noted that the "longitudinal position of maximum body depth, dorsal fin position (position of maximum height) and pupil diameter are highly variable (independent of size variation) in Gastrophryne carolinensis (Holbrook, 1835)". This observation agrees with my results (I did not take into account the pupil diameter in this study, but the eye diameter, which is well correlated with size in $R$. nigrovittata). Studies devoted to the phenotypic plasticity of anuran larvae have shown that certain body and tail proportions (SVL, BH, BW, HT and VT) can vary under different ecological conditions, such as presence of predators, density or an unpredictable environment (Potthoff and Lynch, 1986; Crump, 1989; Inger, 1992; Pfennig, 1992a, 1992b; Relyea and Werner, 2000; Vences et al.,2002).

Table 3. Morphologic characters, stages from which they should be used in taxonomic studies and remarks about the state of characters at this stage.

\begin{tabular}{|c|c|c|c|c|c|c|}
\hline Characters & & & Stage & & & Remarks \\
\hline & 28 & 29 & 30 & 31 & 32 & \\
\hline Marginal papillae & & & $\mathrm{X}$ & & & Definitive number but growth continues until stage 36 \\
\hline Labial teeth & & & & & $\mathrm{X}$ & $\begin{array}{l}\text { Tooth rows with their definitive number of teeth and their } \\
\text { definitive length }\end{array}$ \\
\hline Beak & & $\mathrm{X}$ & & & & Definitive coloration \\
\hline Lateral line & $\mathrm{X}$ & & & & & Appearance \\
\hline Macroglands & & & & $\mathrm{X}$ & & All pairs present \\
\hline Bucco-pharyngeal features & & & & $\mathrm{X}$ & & Most characters present \\
\hline
\end{tabular}




\section{Conclusions}

According to the results presented herein (Table 3), a $R$. nigrovittata tadpole bearing all its potentially useful characters is a tadpole at stage 32 or later, according to the relative length of keratodont rows, which is a valuable character in taxonomy especially in morphologically homogenous groups such as the tadpoles of the genera Bufo or Hyla (Annandale and Rao, 1918; Gosner and Black, 1957; Limbaugh and Volpe, 1957; Zweifel, 1961). The important modifications occurring in the buccopharyngeal cavity from stage 43 onwards (Wassersug, 1976b) - the degeneration of the mouthparts beginning at stages 40 or 41, independently of the genus (Limbaugh and Volpe, 1957; Volpe, 1957; Gosner, 1960; Sedra and Michael, 1961; Zweifel, 1961), and the resorption of tail and cloacal tail piece (stage 41; Gosner, 1960), linked to metamorphosis - prevent the use of tadpoles of these late stages for taxonomic purposes. Therefore, tadpoles in developmental stages from 32 to 40 possess the complete set of characters and only tadpoles in this range should be used for taxonomic and systematic purposes. Earlier stages of tadpoles must be compared only with specimens in the same stage of development.

A taxonomically reliable character can be defined as one that is stable during a part of ontogeny, i.e. showing low variation and being suitable for taxonomic comparisons. Not all such characters are necessarily species-specific. It is the comparative study itself that will establish, among the set of available characters, those that are species-specific for the taxa studied and that are taxonomically or phylogenetically informative. The present study should be useful in pointing to characters and stages that are likely to bear such information. However, it is important to emphasize that all characters are potentially suitable, in the sense that they can be used in certain cases. Also, the variable morphometric characters should be mentioned in the description of a tadpole in order to describe the shape of the animal.

\section{Acknowledgements}

I am grateful to A. Ohler and M. J. Hoyos for their help in the field, to the Frontier staff and research assistants for logistical assistance in the field, and to the Institute of Ecology and
Biological Resources (Hanoi) for providing a permit to export the specimens. I thank G. Mascarell (Muséum, Paris) for technical assistance with the scanning electron microscopy and $\mathrm{M}$. Judson (Muséum, Paris) for a stylistic revision.

\section{References}

Agarwal SK, Niazi IA. 1980. Development of mouthparts in the tadpoles of Rana tigrina Daud. Proc. Indian Acad. Sci. (Anim. Sci) 89: 127-131.

Altig R. 1970. A key to the tadpoles of the continental United States and Canada. Herpetologica 26: 180-207.

Altig R, Johnston GF. 1989. Guilds of anuran larvae: relationships among developmental modes, morphologies, and habitats. Herp. Monogr. 3: 81-109.

Altig R, McDiarmid RW. 1999a. Diversity. Familial and generic characterizations. In: McDiarmid RW, Altig R, eds. Tadpoles. The biology of anuran larvae. The University of Chicago Press, Chicago and London, 295-337.

Altig R, McDiarmid RW. 1999b. Body plan. Development and morphology. In: McDiarmid RW, Altig R, eds. Tadpoles. The biology of anuran larvae. The University of Chicago Press, Chicago and London, 24-51.

Annandale N, Rao CRN. 1918. The tadpoles of the families Ranidae and Bufonidae found in the plains of India. Rec. Ind. Mus. 15: 25-40.

Boulenger GA. 1897-1898. The tailless batrachians of Europe. Vols. $1 \& 2$. Ray Society, London.

Bresler J, Bragg AN. 1954. Variations in the rows of labial teeth in tadpoles. Copeia 1954: 255-257.

Brown HA. 1989. Tadpole development and growth of the Great Basin spadefoot toad, Scaphiopus intermontanus, from Central Washington. Can. Field-Naturalist 103: 531-534.

Chou WH, Lin JY. 1997. Tadpoles of Taiwan. National Museum of Natural Science Special Publication 7: 1-98.

Crump ML. 1989. Life history consequences of feeding versus non-feeding toad larva. Oecologia 78: 486-489.

de Sá RO, Swart CC. 1999. Development of the suprarostral plate of pipoid frogs. J. Morphol. 240: 143-153.

Delaugerre M, Dubois A. 1985. La variation géographique et la variabilité intrapopulationnelle chez Phyllodactylus europaeus (Reptilia, Sauria, Gekkonidae). Bull. Mus. natn. Hist. nat., Paris 4e sér.(A), 7: 709-736.

Dubois A. 1995. Keratodont formulae in anuran tadpoles: proposals for a standardization. J. Zool. Evol. Research 33: 1-15.

Dutta SK, Mohanty-Hejmadi P. 1984. Ontogeny of teeth row structure in Rana tigerina tadpoles. J. Bombay nat. Hist. Soc. 80: $517-528$.

Gaudin AJ. 1965. Larval development of the tree frogs Hyla regilla and Hyla californiae. Herpetologica 21: 117-130.

Glaw F, Köhler J. 1998. Amphibian species diversity exceeds that of mammals. Herpetol. Rev. 29: 11-12.

Glaw F, Köhler J, Lötters S, Vences M. 1998. Vorläufige Liste und Bibliographie neubeschriebener Amphibienarten und -unterarten von 1993 bis 1997. Elaphe 6: 1-24.

Gollmann B. 1991. A developmental table of Crinia signifera Girard, 1853 (Anura, Myobatrachinae). Alytes 9: 51-58. 
Gosner KL. 1959. Systematic variations in tadpole teeth with notes on food. Herpetologica 15: 203-210.

Gosner KL. 1960. A simplified table for staging Anura Embryos and larvae with notes on identification. Herpetologica 16: 183-190.

Gosner KL, Black IH. 1954. Larval development in Bufo woodhousei fowleri and Scaphiopus holbrooki holbrooki. Copeia 1954: 251-255.

Gosner KL, Black IH. 1957. Larval development in New Jersey Hylidae. Copeia 1957: 31-36.

Gosner KL, Rossman DA. 1960. Eggs and larval development of the treefrogs Hyla crucifer and Hyla ocularis. Herpetologica 16: 225-232.

Grillitsch B. 1984. Zur Eidonomie und Differentialdiagnose der Larven von Bufo b. bufo, B. calamita and B. v. viridis im Verlaufe ihrer Entwicklung von der Schlupfreife bis zum Einsetzen der Schwanzreduktion. Unpublished Ph.D. Dissertation, University of Vienna, Austria.

Grillitsch B, Grillitsch H, Dubois A, Splechtna H. 1993. The tadpoles of the brown frogs Rana (graeca) graeca and Rana (graeca) italica (Amphibia, Anura). Alytes 11: 117-139.

Grosjean S. 2001. The tadpole of Leptobrachium (Vibrissaphora) echinatum (Amphibia, Anura, Megophryidae). Zoosystema 23: 143-156.

Haas A. 1996. Das larvale Cranium von Gastrotheca riobambe und seine Metamorphose Amphibia, Anura, Hylidae. Verh. Naturwiss. Ver. Hamburg 36: 33-162.

Haas A. 1997. The larval hyobranchial apparatus of discoglossoid frogs: Its structure and bearing on the systematics of the Anura (Amphibia: Anura). J. Zool. Syst. Evol. Res. 35: 179-197.

Haas A. 2003. Phylogeny of frogs as inferred from primarily larval characters (Amphibia: Anura). Cladistics 19: 23-89.

Haldane JBS. 1955. The measurements of variation. Evolution 9: 484.

Hall JA, Larsen Jr JH, Fitzner RE. 1997. Postembryonic ontogeny of the spadefoot toad, Scaphiopus intermontanus (Anura: Pelobatidae): External morphology. Herpetol. Monogr. 11: $124-178$.

Hammerman DL. 1969. The frog tongue: I. General development and histogenesis of filiform papillae and mucous glands in Rana catesbeiana. Acta Zool. 50: 11-23.

Hampton SH, Volpe EP. 1963. Development and interpopulation variability of the mouthparts of Scaphiopus holbrooki. Amer. Midl. Nat. 70: 319-328.

Hebert PDN, Penton EH, Burns JM, Janzen DH, Hallwachs W. 2004. Ten species in one: DNA barcoding reveals cryptic species in the neotropical skipper butterfly Astraptes fulgerator. PNAS 101: 14812-14817.

d'Heursel A, de Sá RO. 1999. Comparing the tadpoles of Hyla geographica and Hyla semilineata. J. Herpetol. 33: 353-361.

Inger RF. 1956. Some amphibians from the lowlands of North Borneo. Fieldiana Zool. 34: 389-424.

Inger RF. 1992. A bimodal feeding system in a stream-dwelling larva of Rhacophorus from Borneo. Copeia 1992: 887-890.

Kaung HC. 1975. Development of beaks of Rana pipiens larvae. Anat. Rec. 188: 361-370.

Lannoo MJ, Townsend DS, Wasserbug RJ. 1987. Larval life in the leaves: Arboreal tadpole types, with special attention to the morphology, ecology, and behavior of the oophagous $O s$ teopilus brunneus (Hylidae) larva. Fieldiana, Zool. (n.s.) 38: i-iv $+1-31$.

Larson P, de Sá RO. 1998. Chondrocranial morphology of Leptodactylus larvae (Leptodactylidae: Leptodactylinae): Its utility in phylogenetic reconstruction. J. Morphol. 238: 287-305.

Lee JC. 1982. Accuracy and precision in anuran morphometrics: Artifacts of preservation. Syst. Zool. 31(3): 266-281.

Limbaugh BA, Volpe EP. 1957. Early development of the Gulf Coast toads, Bufo valliceps Wiegmann. Amer. Mus. Novitates 1842: $1-32$

Maglia AM, Púgener LA, Trueb L. 2001. Comparative development of anurans: Using phylogeny to understand ontogeny. Amer. Zool. 41: 538-551.

Michalowski J. 1966. Studies on the relationship of Bombina bombina (Linnaeus) and Bombina variegata (Linnaeus). II. Some taxonomic characters of tadpoles of both species and of tadpoles obtained from crosses under laboratory conditions. Acta Zoologica Cracoviensia 11(6): 181-208.

Nichols RJ. 1937. Taxonomic studies on the mouth parts of larval Anura. Illinois Biol. Monogr. 15: 1-73.

Orton GL. 1946. Larval development of the eastern narrowmouthed frog, Microhyla carolinensis (Holbrook), in Louisiana. Ann. Carnegie Mus. 30: 241-247.

Orton GL. 1947. Notes on some hylid tadpoles in Louisiana. Ann. Carnegie Mus. 30: 363-379.

Pfennig DW. 1992a. Proximate and functional causes of polyphenism in an anuran tadpole. Funct. Ecol. 6: 167-174.

Pfennig DW. 1992b. Polyphenism in spadefoot toad tadpoles as a locally adjusted evolutionary stable strategy. Evolution 46: 1408-1420.

Potthoff TL, Lynch JD. 1986. Interpopulation variability in mouthparts in Scaphiopus bombifrons in Nebraska (Amphibia: Pelobatidae). Prairie Nat. 18: 15-22.

Relyea RA, Werner EE. 2000. Morphological plasticity in four larval anurans distributed along an environmental gradient. Copeia 2000: 178-190.

Scott NJ Jr, Jennings RD. 1985. The tadpoles of five species of New Mexican leopard frogs. Occas. Pap. Mus. Southw. Biol. 3: $1-21$

Sedra SN, Michael MI. 1961. Normal table of the Egyptian toad, Bufo regularis Reuss, with an addendum on the standardization of the stages considered in previous publications. Cesk. Morfol. 9: 333-351, 8 pl.

Sokal RR, Braumann CA. 1980. Significance tests for coefficients of variation and variability profiles. Syst. Zool. 29: 50-66.

Strauss RE, Altig R. 1992. Ontogenetic body form changes in three ecological morphotypes of Anuran tadpoles. Growth, Dev. \& Aging 56: 3-16.

Thomas M, Raharivololoniaina L, Glaw F, Vences M, Vieites D. 2005. Montane tadpoles in Madagascar: Molecular identification and description of the larval stages of Mantidactylus elegans, Mantidactylus madecassus, and Boophis laurenti from the Andringitra Massif. Copeia 2005: 174-183.

Tordoff A, Siurua H, Sobey R. 1997. Ben En national park, biodiversity survey 1997. Frontier Vietnam Forest Research Programme Technical Report $N^{\circ} 12$, Society for Environmental Exploration, London and Institute of Ecology and Biological Resources, Hanoi. 
Tubbs LOE, Stevens R, Wells M, Altig R. 1993. Ontogeny of the oral apparatus of the tadpole of Bufo americanus. Amphibia-Reptilia 14: 333-340.

Utsach PC, Mendelson III JR, McDiarmid RW, Campbell JA. 2000. A new species of Hyla (Anura: Hylidae) from the Sierra Mixes, Oaxaca, Mexico, with comments on ontogenetic variation in the tadpoles. Herpetologica 56: 239-250.

Vences M, Puente M, Nieto S, Vieites DR. 2002 Phenotypic plasticity of anuran larvae: Environmental variables influence body shape and oral morphology in Rana temporaria tadpoles. J. Zool. (Lond.) 257: 155-162.

Vences M, Thomas M, van der Meijden A, Chiari Y, Vieites DR. 2005. Comparative performance of the $16 \mathrm{~S}$ rRNA gene in DNA barcoding of amphibians. Frontiers in Zoology 2: article 5 .

Viertel B. 1982. The oral cavities of Central European anuran larvae (Amphibia). Morphology, ontogenesis and generic diagnosis. Amphibia-Reptilia 4: 327-360.

Volpe EP. 1955. A taxo-genetic analysis of the status of Rana kandiyochi Weed. Syst. Zool. 4(2): 75-82.

Volpe EP. 1957. The early development of Rana capito sevosa. Tulane Stud. Zool. 5: 207-225.

Volpe EP, Harvey SM. 1958. Hybridization and larval development in Rana palmipes Spix. Copeia 1958(3): 197-207.

Volpe EP, Wilkens MA, Dobie JL. 1961. Embryonic and larval development of Hyla avivoca. Copeia 1961(3): 240-249.

Wassersug RJ. 1973. Aspects of social behavior in anuran larvae. In: Vial JL, ed. Evolutionary biology of the anurans. Comtem- porary research on major problems. University of Missouri Press, Columbia, 273-297.

Wassersug RJ. 1976a. Oral morphology of anuran larvae: terminology and general description. Occas. Papers Mus. Nat. Hist. Univ. Kansas 48: 1-23.

Wassersug RJ. 1976b. Internal oral features in Hyla regilla (Anura: Hylidae) larvae: an ontogenetic study. Occas. Papers Mus. Nat. Hist. Univ. Kansas 49: 1-24.

Wassersug RJ. 1980. Internal oral features of larvae from eight anuran families: functional, systematic, evolutionary and ecological considerations. Misc. Publ. Mus. Nat. Hist. Univ. Kans. 68: 1-146.

Wassersug RJ. 1989. Locomotion in amphibian larvae (or "why aren't tadpoles built like fishes?”). Amer. Zool. 29: 65-84.

Wassersug RJ, Duellman WE. 1984. Oral structures and their development in egg-brooding hylid frog embryos and larvae: Evolutionary and ecological implications. J. Morphol. 182: 1-37.

Wright AH. 1924. A new bullfrog (Rana heckscheri) from Georgia and Florida. Proc. Biol. Soc. Washington 37: 141-152.

Zweifel RG. 1961. Larval development of the tree frogs Hyla arenicolor and Hyla wrightorum. Amer. Mus. Novitates 2056: 1-19.

Zweifel RG. 1970. Descriptive notes on larvae of toads of the debilis group, genus Bufo. Amer. Mus. Novitates 2407: 1-13.

Received: 14 March 2005

Accepted: 5 September 2005 


\section{Appendix}

List of collection number of specimens

used in this study.

Tadpoles were reared from four different clutches. The collection number of the tadpoles examined are symbolized by different styles (plain, plain*, bold, italic), each style representing a clutch. Stage 26: 1998.5942; 1998.7103; 1998.7104; 1998.7109; 1998.7114; 1998.7119; 1998.7129; 1998.7268. Stage 27: 1998.7124; 1998.7134; 1998.7139; 1998.7144; 1998.7149; $1998.7154 ; 1998.7164 ; 1998.7169$. Stage $28:$ 1998.7159; 1998.7174; 1998.7184; 1998.7189; 1998.7194; 1998.7246; 1998.7340; 1998.7345. Stage 29: 1998.5190*; 1998.5948; 1998.7179; 1998.7199; 1998.7350; 1998.7356; 1998.7381; 1998.7401. Stage 30: 1998.5189*;
$1998.5947 ; 1998.7355 ; 1998.7361 ; 1998.7365 ; 1998.7390 ;$ 1998.7402; 1998.7403. Stage 31: 1998.5192*; 1998.7360; 1998.7366; 1998.7371; 1998.7380; 1998.7386; 1998.7395; 1998.7404. Stage 32: 1998.5191*; 1998.5194*; 1998.5949; 1998.7406; 1998.7407; 1998.7408; 1998.7409; 1998.7410. Stage 33: 1998.5195*; 1998.5950; 1998.5951; 1998.7370; $1998.7375 ; 1998.7411 ; 1998.7412 ; 1998.7413$. Stage 34 : 1998.7414; 1998.7415; 1998.7416; 1998.7417; 1998.7418; 1998.7419. Stage 35: 1998.5198*; 1998.5199*; 1998.5200*; 1998.5952; 1998.5953; 1998.5954; 1998.7385. Stage 36: 1998.5197*; 1998.5201*; 1998.5207*; 1998.5212*; 1998.5240*; 1998.5243*; 1998.5956; 1998.7420. Stage 37: 1998.5204*; 1998.5208*; 1998.5218*; 1998.5226*; 1998.5239*; 1998.5250*; 1998.5957; 1999.4725. Stage 38: 1998.5211*; 1998.5221*; 1998.5238*; 1998.5241*; 1998.5246*; 1999.4726. 